\title{
Relanzamiento de la Revista Psicológica Herediana
}

\section{Relaunch of the Revista Psicológica Herediana}

En los últimos años, se ha experimentado en el Perú un crecimiento en las actividades de investigación científica, asociado a una mayor necesidad de buscar en la ciencia respuestas a los diversos problemas que enfrenta la sociedad. Un medio eficaz para contribuir a esos esfuerzos es la difusión a través de portales web de la versión electrónica de las investigaciones científicas producidas en todas las áreas de conocimiento, ya sean éstas monografías, tesis o artículos de investigación.

La Ley $\mathrm{N}^{\circ} 30220$, Ley Universitaria, en tres de sus cuatro primeros párrafos, indica que las universidades tienen como finalidad primordial realizar investigación científica y docencia en beneficio de la sociedad. Además, desde hace unos años se crearon en el país entidades como la Superintendencia Nacional de Educación Superior Universitaria (SUNEDU), la cual tiene como misión promover una cultura de calidad en la educación universitaria peruana, para contribuir con el desarrollo socioeconómico del país, y el Sistema nacional de Evaluación, Acreditación y Certificación de la Calidad Educativa (SINEACE), el cual se encarga de la evaluación y certificación de las competencias adquiridas dentro o fuera de las instituciones educativas para ejercer funciones profesionales o laborales. Nuestra Facultad ha cumplido todos los parámetros establecidos por el SINEACE logrando la acreditación.

Precisamente, uno de los principales objetivos estratégicos de nuestra Facultad consiste en fomentar y desarrollar una cultura de investigación y propiciar la producción intelectual y su difusión. Por esta razón, el año 2006 se creó la Revista Psicológica Herediana, como órgano oficial de difusión científica de la Facultad de Psicología de la Universidad Peruana Cayetano Heredia, inicialmente sólo en versión impresa y ahora, con la implementación de las nuevas tecnologías en la gestión del conocimiento, también en formato electrónico. Con la publicación de trabajos de investigación que hayan aprobado la revisión por pares y hayan sido elaborados de acuerdo con las normas de redacción de la American Psychological Association (APA), la revista ha logrado hasta ahora se registrada en LATINDEX y en el directorio de LIPECS.

Debido a diversas razones propias de la azarosa vida que puede atravesar una revista, muchas veces se interrumpe el proceso editorial de la misma, debiendo someterse a un proceso de transición y reestructuración. Tal es el caso de la Revista Psicológica Herediana, la cual cuenta ahora con un nuevo Comité Editorial y con impulsos renovados hacia su relanzamiento, cumpliendo los exigentes criterios de calidad establecidos por las bases de datos de documentación en ciencias como LILACS, SciELO, Scopus y otras, para lograr en un futuro cercano su indización en las mismas.

Este nuevo Comité Editorial, luego de analizar las posibilidades que se presentaban para el reinicio de la publicación de la Revista Psicológica Herediana, decidió que éste se produciría el año 2018, por lo que corresponderá a dicho año el volumen 11 de la revista, debiéndose publicar dos números al año a partir de ese momento, lo que permitirá a la Facultad de Psicología de la Universidad Peruana Cayetano Heredia ofrecer a los investigadores en psicología de todo el mundo una revista científica con un portal donde publicar y difundir los resultados de sus investigaciones científicas. 